\title{
TRABALHO RURAL: AS MARCAS DA RAÇA
}

\author{
Maria Aparecida de Moraes Silva
}

Livre-docente aposentada da Unesp, pesquisadora da Capes na pós-graduação

em Sociologia da UFSCar e pesquisadora do CNPq. São Paulo, SP. Brasil.

E-mail:<maria_moraes@terra.com.br>

http://dx.doi.org/10.1590/ 0102-6445139-167/99

O objetivo deste artigo é compreender a permanência da situação de exploração, precariedade e vulnerabilidade que atinge os(as) trabalhadores(as) rurais nas agriculturas do agribusiness do Brasil e de alguns países da América Latina. Permanência do "intolerável", cujo processo de gestação data do momento da conquista da América. Seguindo as reflexões de alguns autores pós-coloniais (Dussel, 1993; Quijano, 2005; Todorov, 1999), o ano de 1492 representou o nascimento da modernidade caracterizada pelo não reconhecimento do outro, ou seja, dos inúmeros povos indígenas que habitavam o continente americano. Portanto, o nascimento do moderno (o europeu, branco) se fez às custas da morte - física ou simbólica - do outro (indígena e, em seguida, do negro africano). Em outras palavras, o nascimento do branco encobre, nega o não branco.

Segundo Quijano (2005, p. 107), dois processos históricos convergiram para a produção da modernidade.

Por um lado, a codificação das diferenças entre conquistadores e conquistados na ideia de raça, ou seja, 
uma supostamente distinta estrutura biológica que situava uns em situação natural de inferioridade em relação a outros [...]. Por outro lado, a articulação de todas as formas históricas de controle do trabalho, de seus recursos e de seus produtos, em torno do capital e do mercado mundial.

Nas palavras de Dussel (1993, p. 44), assim que os territórios eram reconhecidos, passava-se ao controle dos corpos, passíveis de pacificação.

"A conquista" é um processo militar, prático, violento, que inclui dialeticamente o Outro como o si-mesmo. O Outro, em sua distinção, é negado como Outro e é sujeitado, subsumido, alienado a se incorporar à Totalidade dominadora como coisa, como instrumento, como oprimido, como "encomendado", como assalariado (nas futuras fazendas), ou como africano escravo nos engenhos 140 de açúcar e outros produtos tropicais.

A negação do outro justificava a dominação dos corpos e das almas. A ausência da prática da fé cristã era um dos motivos para a escravização. Nas cartas enviadas aos reis de Espanha, Colombo descrevia os indígenas como partes da natureza: árvores, pássaros, animais e índios. As mulheres eram contadas como cabeças de gado. A desumanização do índio era a chave para justificar a escravização e o genocídio ${ }^{1}$. Do mesmo modo, Pero Vaz de Caminha (1963) se referia aos índios como "animais monteses", "pardais do cevadouro", "gente bestial”, "esquiva”, "aves" ou "alimárias montesinhas" que necessitavam ser "amansados".

\footnotetext{
1 Em 1500, a população do globo era em torno de 400 milhões de pessoas, dos quais 80 milhões habitavam a América. Em meados do século XVI, havia cerca de 10 milhões em território americano, logo, um extermínio de 70 milhões em 50 anos! (cf. Todorov, 1999, p. 158).
} 
Nas primeiras décadas do século XIX, Hegel escreve Leciones sobre la filosofia de la história universal. Nessa obra, o filósofo alemão tece reflexões, em forma de aulas ministradas aos seus alunos entre 1822 a 1827, sobre os povos dos cinco continentes. No que tange ao continente americano, faz uma distinção entre América do Norte e América do Sul, ressaltando as maiores qualidades da primeira em relação à segunda. Em relação aos povos sul-americanos, afirma:

Na Europa, vemos esses povos transitarem sem espírito e praticamente incapazes de educação. A inferioridade desses indivíduos se manifesta em tudo, inclusive em sua estatura. Somente as tribos meridionais da Patagônia possuem uma natureza forte, porém subsumida ao estado natural de selvageria e incultura (Hegel, 1946, pp. 173-74; tradução nossa).

No que tange ao Brasil, Hegel (1946, p. 174) se reporta aos negros africanos destinados aos trabalhos rudes, porém eram mais sensíveis à cultura europeia do que os índios, considerados crianças imaturas ${ }^{2}$.

Essas representações foram ao longo da história adquirindo vários matizes. $\mathrm{O}$ importante, nos limites deste texto, é reter que, na verdade, não houve um encontro entre duas culturas diferenciadas. Tratou-se muito mais de um desencontro, de um "choque devastador, genocida, absolutamente destruidor do mundo indígena” (Dussel, 1993, p. 64). Em paralelo aos africanos aportados no Brasil e ilhas caribenhas, nas colônias do sul da Nova Inglaterra eram camponeses livres aprisionados por comerciantes. Formava-se assim, o "triângulo da morte": os navios europeus partiam de Londres, Lisboa, Havre ou Amsterdã, carregados de armas,

2 Menciona o negro brasileiro Dr. Kingera, que levou a quinina ao conhecimento dos europeus. 
e trocavam-nas nas costas ocidentais da África por escravos, os quais eram vendidos em troca do ouro e prata e outros produtos tropicais, entre eles o açúcar (Dussel, 1993, p. 163).

A negação do outro - indígena e africano - deve ser analisada, mormente, a partir do despojamento do ser, enquanto ser social. A negação da língua, da cultura, da história e a consequente redução do sujeito à mercadoria foram, aos poucos, gerando o processo civilizador colonial, marcado pela raça, matriz geradora da sociogênese e psicogênese, que estão impregnadas na pele e nas identidades e subjetividades de milhões de homens e mulheres, herdeiros dessa história. A internalização da negação, da inferioridade, da condição de coisa, portanto, a modelagem do ser social operou-se por meio da violência, da servidão e da escravização. Ainda que houvesse ao longo do tempo revoltas coletivas e individuais, essas marcas ainda estão nos corpos e almas, e o olhar do branco, do dominador ainda os enxerga como portadores da 142 inscrição interior da exterioridade, de um "andar sem espírito", tal como Hegel os via há mais de 200 anos.

Segundo Marx (1978, p. 173), o capitalismo surge quando a força de trabalho se constitui como mercadoria. Portanto, um dos pressupostos desse sistema é que o portador dessa mercadoria seja livre (formalmente), ou seja, que as formas pretéritas, tais como servidão e escravidão, tenham sido abolidas $^{3}$. Todavia, a força de trabalho, além de ser uma mercadoria especial, dado que ela cria valor, não pode ser separada da pessoa do seu possuidor. Todo ser humano é um ser social,

\footnotetext{
3 O modelo abstrato da teoria do valor de Marx, calcado na produção do mais valor - mais-valia - leva em conta apenas trabalhadores livres, a partir do exemplo inglês. Contudo, a escravidão e servidão existentes nas Américas e outras partes do mundo, forneceram as bases para o processo de acumulação do capitalismo europeu. Ainda que essa realidade histórica tenha sido analisada em $O$ capital, no capítulo sobre a acumulação primitiva, portanto como algo que precedera o capitalismo, na verdade se tratava não de um elemento passado, mas consubstancial do capitalismo. Assim, estamos de acordo com o debate sobre a teoria do valor e o processo de acumulação levado a cabo por Rosa Luxemburgo, segundo a qual tais formas de exploração do trabalho são partes do processo de valorização do capital e não anomalias.
} 
ou seja, pertence a uma família, uma cidade, uma pátria, possui uma fé religiosa e política, enfim, tantas inserções que definem a particularidade que está inscrita no ser social (cf. Durkheim, 1970, p. 85). Nesse sentido, é impossível conceber a força de trabalho tão somente da perspectiva econômica da mercadoria, do homem abstrato, desprovido de suas particularidades físicas, psíquicas e sociais. Para Marx, o valor da força de trabalho é variável, segundo as condições históricas de cada país ou região. No entanto, uma das condições que difere a força de trabalho das outras mercadorias é ser ela possuidora de um valor histórico e moral (cf. Marx, 1978, p. 174). Em outros termos, a força de trabalho possui marcadores históricos e sociais (raciais, de gênero, idade etc.).

Trata-se, ao fim e ao cabo, do encobrimento, da negação do outro. Porém, não é apenas ocultamento, mas também um processo de produção material e simbólica do outro. Esse processo moral e histórico, segundo Marx, define o valor - ou melhor, o menos valor - dessa mercadoria no mercado de trabalho. É evidente que isso não ocorre de forma pacífica. Desde os tempos coloniais, pensando na história latino-americana, houve guerras e muitos conflitos contra a dominação e a usurpação das relações sociais existentes pelos colonizadores. É um processo marcado pela violência, desde a sua gênese até os dias de hoje.

A formatação, o enquadramento dos indivíduos, não se faz sem as normas institucionais. As mãos do Estado produziram legislações e outras normativas para regularizar a mercantilização do trabalho, desde os governos coloniais as "encomiendas", a escravidão, a peonagem - até as migrações e emigrações em vários países do continente. Além dessas normativas, as incontáveis formas de disciplinamento e controle postos em prática contribuíram para o processo de coisificação de homens cujo "andar é sem espírito”, de seres abstratos, que, sequer, em muitas ocasiões, fazem parte das estatísticas oficiais de trabalho e emprego. 
Retomado as considerações de Quijano (2005, p. 110), na América houve a colonialidade do controle do trabalho, baseada na classificação racial, segundo a qual o trabalho pago era afeito aos brancos, europeus, e o não pago aos negros e índios. A gênese histórica da colonialidade/racialidade do trabalho é uma ferramenta importante para a compreensão do que ocorre na fase do "moderno sistema-mundo" capitalista (cf. Wallerstein, 1989), onde as "raças inferiores" são as maiores vítimas da precarização e, não raro, da submissão às condições análogas às de escravo.

Em 1711, foi publicado em Portugal, o livro de André João Antonil, Cultura e opulência do Brasil, que sofrera a perseguição do Estado, condenando-o à fogueira ${ }^{4}$. Esse livro faz uma excelente etnografia da agricultura, sobretudo das plantações de cana-de-açúcar, dos engenhos, da mineração, das plantações de tabaco e da criação do gado. Retrata a vida econômica e social do Brasil em princípios do século XVIII. 144 A parte referente ao açúcar está dividida em três livros. No primeiro, o autor se refere às plantações de cana, com os escravos, feitores e os senhores; no segundo, analisa a fabricação do açúcar; no terceiro, trata do produto, o açúcar. São trinta e seis capítulos dedicados à cultura da cana-de-açúcar.

Em todos os capítulos, há menção ao trabalho escravo de homens e mulheres, às formas disciplinares, às violências exercidas e a exaltação divina do açúcar mercadoria. Há uma descrição minuciosa da pirâmide social em cujo topo está o senhor de engenho e sua família. Há menções sobre os comerciantes, eventuais hóspedes do engenho. No tocante ao processo de trabalho, tanto na agricultura como na industrialização, a descrição contempla desde a qualidade da terra, dos animais, dos instrumentos, da

\footnotetext{
4 Da edição de 1711, restam apenas seis exemplares: um em Paris; outro em Londres; outro na Biblioteca Nacional de Lisboa; um na Biblioteca Nacional do Rio de Janeiro; dois na Faculdade de Direito da USP, em São Paulo (cf. Dimas, 1992, p. 135). Antonil era o pseudônimo do padre jesuíta italiano João Antônio Andreoni.
} 
divisão do trabalho, dos trabalhadores qualificados e dos escravos e escravas.

Reproduzimos doravante a brilhante análise estilística feita por Dimas (1992, pp. 139 ss.) sobre o livro de Antonil. Elegemos alguns temas para espreitar a natureza do trabalho e a (não) condição do humano no engenho real de Sergipe do Conde, situado no Recôncavo Baiano.

A fornalha: lugar agigantado e transformado em "purgação dos pecados". Ouçamos as palavras dojesuíta, primeiramente:

Nem faltam perto destas fornalhas seus condenados, que são os escravos boubentos e os que têm corrimentos, obrigados a esta penosa assistência para purgarem com suor violento os humores gálicos de que têm cheio seus corpos. Veem-se a, também outros escravos, facinorosos, que, presos em compridas e grossas correntes de ferro, pagam neste trabalhoso exercício os repetidos excessos da sua extraordinária maldade, com pouca ou nenhuma esperança de emenda (Antonil, p. 115).

Agora, a interpretação de Dimas (p. 140):

Dupla função tem, portanto, o calor da fornalha: a produção do açúcar branco e a purgação do homem preto. $\mathrm{Na}$ antinomia cromática materializa-se a condição qualitativa de cada um perante o branco, cujo imaginário ancestral já se habituara a identificar o "escuro" como pecado, e o "claro" com a virtude. Nada mais "natural”, pois, que junto à fornalha o escravo atingisse a alvura depois de bem cozido.

\section{Fragmentação do escravo:}

Os escravos são as mãos e os pés do senhor do engenho, porque sem eles no Brasil não é possível fazer, conservar e aumentar a fazenda, nem ter engenho corrente [...]. 
Por isso é necessário comprar cada ano algumas peças e repartilas pelos partidos, roças, serrarias e barcas (Antonil, p. 89).

A fragmentação é também moral: ladinos/boçais, bons/maus, fracos/robustos, grosseiros/meticulosos, enfim, os negros são vistos de forma decomposta. "Negro não é gente; negro é peça e peça que se ajusta à máquina e que por ela já foi tipificado e enquadrado" (Dimas, p. 142).

O negro é, portanto, visto como coisa, peça, pedaço, fragmento. Ao contrário, o açúcar/mercadoria é humanizado e até mesmo divinizado, tal como aparece no último capítulo, referente a uma verdadeira saga da produção da cana, desde seu nascimento até sua transformação dolorosa em açúcar, o transporte perigoso pelo mar, passando pelo perigo em ser abocanhado pelos mouros infiéis (Dimas, p. 144).

No início do texto, Dimas (pp. 134, 135) lança duas interrogações sugestivas para a análise sociológica. Seria a 146 civilização criada pelo açúcar responsável pela produção de um imaginário que até hoje se cultiva nesse país? Ou esse imaginário está muito mais vinculado às relações de trabalho criadas para sustentar essa agricultura desde seu nascimento? Embora ele não tenha se proposto a respondê-las, tomaremos a segunda questão como um ponto importante para a análise da colonialidade do trabalho vis-à-vis os marcadores raciais - indígena e negro - nos campos do Brasil e de alguns países latino-americanos.

\section{Marcadores atuais e formas de trabalho}

Ainda que, atualmente, o campo brasileiro venha sendo representado pela gigantesca produção de commodities, configurando o processo de reprimarização da economia, o trabalho responsável por essa produção não tem ocupado lugar de destaque na agenda de muitos estudiosos. Em geral, chama ainda a atenção, em razão de situações impensáveis, as formas de escravidão por dívida - a peonagem -, vigente nas regiões de 
fronteira agrícola e em atividades relativas ao desmatamento, mineração, formação de pastagens e carvoarias, tema analisado por muitos pesquisadores, sobretudo em décadas passadas (Esterci, 1994; Figueira, 1986; Martins, 1979, 1995; Barrozo, 1992, entre outros $)^{5}$. Como já salientara o professor José de Souza Martins (1995, pp. 6-9), a escravidão atual não é mera sobrevivência de relações arcaicas; ao contrário, faz parte do próprio processo de reprodução ampliada do capital.

Nosso intento não é partir de uma definição prévia desse trabalho, e nem analisá-lo pela ótica das relações de classe (isso já foi realizado pelos autores citados), mas abordá-lo à luz das considerações feitas sobre a raça, presentes no imaginário social, entendido como construção material e simbólica. Assim, esse posicionamento não significa subsumir as categorias classe e gênero, mas considerá-las consubstanciais à raça. Primeiramente, serão tecidas breves considerações sobre a peonagem, como exemplo de violência aberta e escravidão, e, em seguida, será analisado o trabalho assalariado nos canaviais, como violência dissimulada, invisível. A colonialidade é constituída por ambas as formas.

As publicações recentes dos Conflitos do campo pela CPT revelam que as situações de escravidão por dívida, o impedimento do direito de ir e vir, as ameaças de morte, a violência física e moral, os maus tratos, o desrespeito aos direitos trabalhistas, o tratamento de coisa impingido aos trabalhadores ainda continuam. No entanto, não se manifestam apenas em tarefas de formação de fazendas na fronteira agrícola, nos garimpos clandestinos ou em carvoarias,

\footnotetext{
5 No que se refere à peonagem, organizações religiosas e civis, como a Comissão Pastoral da Terra (CPT) e o Repórter Brasil (<http://reporterbrasil.org.br/>), têm divulgado denúncias de superexploração e trabalho escravo ocorrentes em todas as regiões do país - e não apenas em seus confins -, inclusive no meio urbano. Os relatórios Conflitos no campo, da CPT, publicados desde 1985, estão disponíveis em: <https: / /drive.google.com/folderview?id=0Byo7P47EvrO9ZU1BdHpMUFVN N00\&usp=sharing $>$. Sobre trabalho escravo, ver o dossiê disponível em: <http:// ojs.statsbiblioteket.dk/index.php/bras/issue/view/1881/showToc>.
} 
como também nas plantações de tomate em Santa Catarina, de cana-de-açúcar em vários estados, inclusive em São Paulo. Como diz o professor Martins, "o capital pode não só preferir o trabalho não livre” (Martins, 1995, p. 6).

O perfil dos trabalhadores envolvidos em situações de escravidão mostra que a maioria é proveniente dos estados de Minas Gerais, Goiás, Maranhão, Piauí, Bahia, além de outros estados do nordeste (cf. Silva et al., 2011). Esse dado é revelador dos marcadores de raça/etnia desses trabalhadores. Não são em geral, brancos. "Não valem nada", consoante as palavras de um "gato". A proibição do direito de ir e vir se manifesta por meio do isolamento espacial, da presença de capangas armados, ameaças diretas ou simbólicas, como a de um gerente/capitão do mato: "aquele que anda no chão deixa rastros, aquele que voa faz sombra”, insinuando que não haveria como escapar de sua perseguição. E mais ainda, a retenção costumeira da carteira de trabalho representa 148 uma forma de lhes retirar a identidade de trabalhador, cuja posse fica em domínio do proprietário do empreendimento. Estar ou ficar sem carteira significa estar sem passaporte, sem reconhecimento, portanto, estar mais ainda vulnerável. A fuga, muitas vezes, não ocorre porque a carteira está presa, pois fugir sem ela é o mesmo que deixar uma parte de si para trás. Portanto, a retenção da carteira é uma das correntes invisíveis do sistema de exploração e dominação imposto. É uma forma de ocultá-lo, negá-lo. É a perda da alforria, da autonomia.

Ademais da peonagem, há outras formas de trabalho também "preferidas" pelo capital. Focaremos doravante a análise no trabalho dos canaviais, objeto de nossas pesquisas durante mais de três décadas.

\section{Panorâmica do trabalho nos canaviais}

A substituição das fazendas cafeeiras no Estado de São Paulo pelas grandes empresas/usinas de cana-de-açúcar ocorreu a partir de meados dos anos de 1950 (Silva, 1999). Desde 
então, essa cultura ocupou mais de 6 milhões de hectares de terra. "Um verdadeiro mar de cana”. De lá para cá, milhares de camponeses e camponesas deixaram suas terras para o trabalho nos canaviais paulistas. Muitos deixaram a família para trás, como meio de garantia da reprodução social. Aqueles vitimados pela expropriação de suas terras chegaram com as famílias. Esse fato provocou uma mudança no aspecto cromático da classe trabalhadora rural paulista. Não mais estavam em cena os descendentes de colonos europeus e brancos, mas "a gente dos países do norte", a "baianada", a "mineirada", a "negrada". Desde seus primórdios, o trabalho nos canaviais caracterizou-se pela precariedade, insalubridade e vulnerabilidade. Até os anos 1980, antes das greves de Guariba (1984, 1985), em São Paulo, os trabalhadores eram alojados em barracões, ou cortiços insalubres, muitas vezes em antigos chiqueiros de porcos ou armazéns, ao lado de agrotóxicos ${ }^{6}$. Em seguida, foram construídos alojamentos, capazes de albergar de 200 a 800 homens no meio dos canaviais, controlados por uma disciplina severa, semelhante ao que Erving Goffman (1987) denominou de "instituição total". A grande maioria é constituída por migrantes temporários, que vivem como andorinhas (Silva, 1992).

O processo de socialização para o trabalho nos canaviais se passa em três momentos:

(1) A arregimentação é feita pelo "gato", (re)conhecedor dos trabalhadores. É sua função conhecer os "bons”, ou seja, aqueles que produzem muito, que possuem boa saúde física, não causam encrencas, não participam de greves, não bebem, são obedientes às regras. Enfim, seu conhecimento passa pelo crivo moral. A escolha é feita segundo as cotas exigidas pela usina e a quantificação é referenciada pelo

6 Com o passar dos anos, graças às denúncias da Pastoral dos Migrantes ao Ministério Púbico e à Vigilância Sanitária, as usinas construíram alojamentos, pondo fim aos barracões. 
número de cabeças. Do mesmo modo que os escravos do engenho Sergipe do Conde, visitado por Antonil, o sistema de classificação é baseado nas antinomias, nas oposições. O processo de escolha das cabeças que comporão a cota fixada pela usina fixa-se no corpo físico, algo semelhante à época da escravidão.

(2) No eito, o processo disciplinar é feito por fiscais, turmeiros, feitores e por computador, mais recentemente. Controla-se a quantidade de cana cortada, a curvatura do corpo para garantir a qualidade do corte ao rés do chão. A figura do "bom" cortador, do "podão de ouro", contradiz a do "mau" cortador, do "podão de borracha", objeto de humilhação dos próprios colegas de trabalho.

(3) Nos alojamentos, as técnicas disciplinadoras são impostas pelos "guardas", geralmente ex-turmeiros e pessoas de confiança da usina. Na verdade, são investidos nesta função. Além da vigilância contínua sobre coisas e pessoas 150 (evitar o uso de bebidas alcoólicas, porte de armas, brigas, presença de mulheres, bagunça nos quartos, muito tempo para tomar banho, barulho à noite etc.), tem a obrigação de "comunicá" tudo aos técnicos de segurança. Dispositivos de comunicação, tais como rádios, instalados nos carros dos técnicos e nos alojamentos, por meio de um sistema de comunicação centralizada, além dos registros do quantum de cana cortada, afixados na entrada do alojamento e também nos ônibus, dão conta do desempenho de cada um, tanto no espaço produtivo, como no reprodutivo. Essa é a forma de "expulsar o camponês do proletário" (Silva, 1990, pp. 5-11). A formatação do canavieiro, do "bom" cortador, é um processo que consiste em esvaziar a estrutura moral e afetiva dos camponeses. As estratégias disciplinares visam à redução do corpo à energia para cortar a média (cota) estabelecida. Atualmente, existem poucos alojamentos no interior das áreas de cana, em função da diminuição drástica do número de migrantes, causada pelo aumento do processo de mecani- 
zação do corte manual ${ }^{7}$. Os que chegam são destinados às “casas das usinas" nas cidades. Aí também ocorrem os mesmos critérios disciplinares expostos. Contudo, após 2009, com a assinatura do Compromisso Nacional para Aperfeiçoar as Condições de Trabalho nos Canaviais, firmado entre o governo federal, representantes da ÚNICA (União da Indústria Canavieira $)^{8}$ e dos trabalhadores, foi implantado o que denominamos mercado de trabalho temporário regulado pelo Estado. Assim, visando eliminar a figura dos intermediários ("gatos"), os trabalhadores passaram a ser contratados diretamente nos locais de origem pelas usinas e, logo, transportados até os locais de trabalho. Na verdade, esse acordo visava melhorar a imagem do setor canavieiro no comércio exterior, manchada por denúncias de mortes de trabalhadores ocorridas devido ao excessivo esforço durante a jornada ${ }^{9}$. Era uma forma de mascarar o processo de superexploração vigente, traduzido na imposição da produtividade hoje em torno de 12 a 15 toneladas de cana cortadas por dia durante 10 meses ao ano. A figura do "gato" continuou existindo nos locais de origem, e é ele quem arregimenta o número de trabalhadores exigidos por cada empresa, os quais são examinados pelo médico antes de serem contratados e registrados (cf. Silva, 2013). É uma forma de controlar o mercado de trabalho, segundo a demanda, e também evitar que as famílias dos trabalhadores

\footnotetext{
7 Entre 2007 e 2012, caiu 37,1\% o número de trabalhadores canavieiros, mesmo período em que houve intensificação do processo de colheita mecânica de cana-de-açúcar, tendência constatada entre as empresas sucroalcooleiras do Estado de São Paulo. O número desses trabalhadores por mil hectares de área colhida de cana-de-açúcar vem diminuindo ano a ano, de forma que, em 2012, sua necessidade revelava-se 47,64\% menor que em 2007 (cf. Baccarin et al., 2013, p. 2).

8 Disponível em: <http://www.secretariageral.gov.br/.arquivos/publicacaocanadeacucar.pdf >; acesso em: 12 dez. 2009.

9 No período de 2003 a 2013, foram registradas 23 mortes de cortadores no Estado de São Paulo, supostamente por excesso de trabalho. Essas denúncias originaram-se de nossas pesquisas e da Pastoral dos Migrantes. Jadir Damião Ribeiro, então bolsista de iniciação científica do CNPq, foi quem constatou que todas essas mortes haviam decorrido de dores provocadas por cãibras, denominadas birôla ("canguru", no Estado de Alagoas).
} 
os acompanhem, pois tanto nas "casas da usina", como nos alojamentos, a presença de mulheres e crianças é interditada. Vale ainda acrescentar que o sistema imposto é o de 5x1, cinco dias trabalhados e um de descanso. Assim, a sociabilidade entre os trabalhadores fica fragmentada, dado que a divisão em turmas e turnos impede que o dia de folga seja o mesmo para todos. Sob a batuta do Estado, constituiu-se o mercado de trabalho regulado, uma vez que o contrato só pode ser feito nos locais de origem, o que faz com que, após a safra, os trabalhadores sejam obrigados a regressar, confirmando, assim, a migração permanentemente temporária.

Além da exploração da força de trabalho evidente nos baixos salários recebidos ${ }^{10}$, há a fragmentação da família, o que corresponde à apropriação do afeto (Silva, 2014). Essa estratégia, além de garantir maiores lucros, por a reprodução familiar não entrar no preço da força de trabalho, causa fraturas na estrutura de sentimentos tanto dos homens que partem quanto das 152 mulheres e filhos que ficam. Retomando a figura da fornalha à qual os escravos eram acorrentados para se purificar de suas feridas e desobediências, esse sistema, legitimado pelo Estado, reproduz os mesmos objetivos, cujas correntes são invisíveis. O não cumprimento da média imposta corresponde à dispensa, o que causaria perdas financeiras, além de dificuldades futuras em conseguir emprego em outra empresa. Quanto aos danos físicos, as pesquisas apontam problemas cardiorrespiratórios (Barbosa, 2010; Verçoza, 2016), dores musculares, tendinite, problemas na coluna, pernas e braços, câncer, além de danos psíquicos, alcoolismo e uso de drogas. Como impacto na saúde das mulheres que não migram, foram verificados casos de depressão, alcoolismo e melancolia (Silva, 2015). A melancolia é a doença da alma, produz o desassossego, o alheamento, a indiferença em relação ao mundo. Do mesmo modo que queimam e cortam a cana, os trabalhadores queimam e cortam a si

${ }^{10}$ Atualmente (em 2016), o pagamento de 1 tonelada de cana está em torno de $\mathrm{R} \$ 4,00$. 
mesmos. Muitos afirmam que no final da safra estão reduzidos a bagaço; outros que ficam com os nervos esgotados, sem o suco, tal como a cana.

Como já dito, o salário pago é inferior às necessidades de reprodução familiar. Compreende-se que a estratégia empresarial de buscar trabalhadores a mais de 3 mil quilômetros, como no caso dos maranhenses, é uma forma de aumentar os lucros e externalizar os custos dessa reprodução para os locais de origem dos mesmos. Desse modo, compreende-se também a importância das migrações temporárias para alimentar a reprodução ampliada dos capitais (cf. Meillassoux, 1976; Wallerstein, 2006, pp. 192 ss.). Por outro lado, a nomeação de migrante ofusca a classificação étnico/racial. A predominância da ideologia baseada no mascaramento racial, isto é, da falsa ideia de democracia racial, corrobora para a reprodução do menos valor da força de trabalho de centenas de milhares de nordestinos(as) e mineiros(as) que laboraram nos canaviais paulistas ao longo das últimas sete décadas. Sob a capa de migrante, esconde-se o outro, o não branco, o não paulista. Os traços culturais (crenças, valores, símbolos, jeito de falar, práticas culinárias, ritos, festas) que definem os migrantes só são percebidos como inferiores quando se defrontam com o outro. Portanto, a etnicidade é dinâmica, mutável e histórica. A abolição jurídica da escravatura não correspondeu à abolição dos elementos constitutivos do imaginário social, cuja gênese colonial esteve vinculada às relações de trabalho criadas para sustentar a economia agrícola. Em vez da nomeação de negro, mestiço, emprega-se a de migrante. O negro e o mestiço permanecem obnubilados. É esse ofuscamento que justifica a permanência da colonialidade do trabalho.

Segundo Quijano, as diferenças entre os conquistadores e conquistados foram codificados na ideia de raça, posicionando os conquistados num lugar inferior biologicamente, com base em seus traços fenotípicos e culturais. Nesse processo de naturalização das estruturas biológicas diferentes, a raça operaria 
como critério fundamental da distribuição racista da população nas hierarquias, lugares e papéis sociais na nova estrutura de poder formada com o mundo colonial. Haveria, assim, uma cristalização morfológica das posições (cf. Quijano, 2005, pp. 107-109). Em outros termos, foi gerada a divisão étnica do trabalho, pela qual os negros e indígenas eram destinados às tarefas não pagas como a servidão e escravidão.

A raça aparece como o principal elemento para garantir a eficácia da dominação física, material e subjetiva, transformando os conquistadores brancos (europeus) em dominadores e os outros em dominados. A raça passa a demonstrar que "é o mais eficaz e durável instrumento de dominação social e universal” (Quijano, 2005, pp. 107-108). Ainda, segundo o autor, a raça está inscrita no corpo, na pele, na subjetividade. A eficácia da dominação é um requisito para a exploração. "Raça e trabalho" aparecem como naturalmente associados na racialidade do trabalho, como nova 154 tecnologia de dominação/exploração (p. 109).

Do mesmo modo, Guimarães (2003, p. 96) faz as seguintes pontuações sobre raça:

São discursos acerca das origens de um grupo que usam termos que remetem à transmissão de traços fisionômicos, qualidades morais, intelectuais, psicológicas etc. [...] Há outros discursos acerca dos lugares: lugares geográficos, de origem [...], o lugar onde se vive e que permite nossa identificação com certo grupo de pessoas. Quando falamos de lugares, falamos de etnias.

E, acerca da cor da pele, afirma:

Meu argumento é o seguinte: "cor" não é uma categoria objetiva, cor é uma categoria racial, pois quando se classificam as pessoas como negros, mulatos ou pardos é a ideia de raça que orienta esta classificação. Se pensarmos 
em "raça" como uma categoria que expressa um modo de classificação baseado na ideia de raça, podemos afirmar que estamos tratando de um conceito sociológico, certamente não realista, no sentido ontológico, pois não reflete algo existente no mundo real, mas um conceito analítico nominalista, no sentido que se refere a algo e orienta e ordena o discurso sobre a vida social (Guimarães, 2003, pp. 103-104).

Considerar raça um conceito analítico nominalista, que orienta e ordena o discurso, é uma ferramenta importante para compreender o menos valor da força de trabalho de nordestinos e mineiros do Vale do Jequitinhonha nos canaviais paulistas, tendo em vista que o marcador - cor da pele - desmistifica a ideia abstrata do valor dessa força de trabalho e justifica a dominação/exploração vigente.

\section{Às mulheres, tarefas "leves" ...}

As mulheres foram praticamente alijadas do corte manual, principalmente em razão do aumento da mecanização. Contudo, elas desempenham tarefas pesadas, insalubres e invisíveis. A divisão sexual do trabalho imposta lhes determina as tarefas:

(1) recolha da "bituca", os restos de cana deixados pelas máquinas. Trata-se de uma atividade penosa, pois as mulheres trabalham agachadas durante toda a jornada. Essa atividade é de suma importância para evitar a proliferação de bactérias que possam comprometer a rebrota da cana ${ }^{11}$;

(2) “abrir o eito". É uma tarefa que consiste em arrancar o mato nas bordas dos canaviais e também nas curvas de nível ${ }^{12}$ para facilitar o início do corte feito pelas máquinas;

\footnotetext{
11 A cana é uma gramínea que brota logo após o corte. Segundo a variedade, a rebrota pode ocorrer até seis ou sete vezes.

${ }^{12}$ Curvas de nível são sulcos feitos no terreno para evitar a erosão provocada pelas águas das chuvas. Muitos depoimentos revelam que as mulheres retiram as canas dos sulcos, mesmo que os mesmos estejam cheios de água. Atualmente, com as mudanças do processo de trabalho, os terrenos são aplainados para facilitar as manobras das máquinas e, com isso, não são feitas curvas de nível.
} 
(3) distribuição de herbicidas. As mulheres carregam nas costas bombas de veneno (20 litros) e o distribuem nas bordas e também no meio da cana. É um trabalho insalubre devido ao manuseio do veneno e também das dores na coluna devido ao peso do equipamento;

(4) "arrancar colonião". É uma tarefa que exige muito esforço, já que esse capim (Panicum maximum), que cresce entre as fileiras de cana, tem raízes profundas, inviabilizando o uso de herbicidas para eliminá-lo, necessitando assim ser arrancado com enxadão;

(5) plantio da cana. Após os sulcos feitos por tratores, as mulheres vão colocando as mudas nos mesmos. Atrás delas, os tratores vão tapando os sulcos. É um trabalho cuja intensidade é determinada pelo ritmo dos tratores;

(6) recolha de pedras. Consiste em retirar as pedras do terreno antes da entrada das máquinas. As mulheres vão recolhendo as pedras, colocando-as em baldes que serão levados 156 até os carreadores ${ }^{13}$. É um trabalho pesado, pois as pedras chegam a pesar até cinco quilos, feito no meio dos pés de cana, além de perigoso, em razão de cobras e escorpiões que, com frequência, estão alojados sob as pedras. Este trabalho é de suma importância, pois evita que as lâminas das máquinas sejam danificadas pelas pedras. É considerado um trabalho escravo pelas mulheres. Elas se sentem envergonhadas e humilhadas. Muitas silenciam, preferem dizer que "trabalham na roça”, não revelando os detalhes das atividades desenvolvidas. Outras preferem se referir a terceiros, "conhece alguém que cata pedra”, não assumindo a autoria do trabalho.

Todas essas tarefas estão eivadas pelo crivo das discriminações e estereótipos do gênero feminino. São tidas como leves, afeitas às mulheres - dado que elas são mais caprichosas que os homens -, que, portanto, recebem salários menores.

\footnotetext{
${ }^{13}$ Carreadores são "ruas" largas entre os eitos de cana, por onde transitam as máquinas, tratores, guinchos, ônibus que transportam os trabalhadores etc.
} 
Vale ainda dizer que os homens possuem um contrato laboral de dez meses ao ano e recebem segundo a produção. As mulheres são pagas pela diária. No entanto, o quantum de trabalho é determinado pelos fiscais, logo, a diária mascara a remuneração por produção. Outro dado importante é que, com o avanço da mecanização do corte, houve mudanças no processo e na organização do trabalho. Assim, o que vige nos canaviais são as "turmas ambulantes", que desempenham essas distintas atividades, exceto o corte da cana ${ }^{14}$, sob a rubrica "trabalhos gerais", registrada em carteira. Muitas são contratadas por firmas terceirizadas, que, além da cana, empregam as mulheres na colheita da laranja, cebola, manga, tomate, segundo os respectivos ciclos produtivos, e na distribuição de venenos nas plantações de eucaliptos. Trata-se de um trabalho permanente com contrato temporário.

Ademais dos marcadores de gênero, as mulheres que exercem tais atividades são negras, mestiças, não brancas. Elas carregam os estigmas das três organizações sociais consubstancialmente: classe/gênero/raça. São alocadas em atividades aviltantes, recebem menores salários e sofrem discriminações pelo fato de serem negras (cf. Silva, 1999).

\section{A realidade de outros países}

Segundo Gaudemar (1977), a força de trabalho deve ser livre sob dois pontos de vista: a liberdade positiva e a negativa. A primeira se reporta ao direito de ir e vir e diz respeito ao fato de que o possuidor da força de trabalho possa vendê-la a quem lhe aprouver; a segunda, no entanto, reporta-se ao fato de que o possuidor só tendo uma única mercadoria, ele não tem outra hipótese a não ser vendê-la, "na prática, ou vende a sua força de trabalho para viver, ou não a vende e morre"

\footnotetext{
${ }^{14}$ Há muitos outros trabalhos nos canaviais: tratoristas, caminhoneiros, operadores das máquinas colhedoras, mecânicos, trabalhadores empregados na distribuição da vinhaça, na segurança, sem contar os fiscais, feitores e turmeiros, responsáveis pelo controle do trabalho e dos trabalhadores (Silva et al., 2014).
} 
(Gaudemar, 1977, p. 190). Essa concepção afasta-se daquela que vê o mercado de trabalho como fixo e pontual. Ao contrário, fornece as ferramentas à compreensão da mobilidade capitalista do trabalho. A mobilidade surge então como condição necessária, se não suficiente para o surgimento do capitalismo e como um índice de seu desenvolvimento (cf. Gaudemar, 1977, p. 192). Essa ideia não está em contradição ao que afirmamos sobre a peonagem. Vimos que ela não se constitui como anomalia ao capitalismo, mas faz parte de seu processo de reprodução. Na verdade, é a duplicidade constitutiva de liberdade (positiva e negativa) que garante a mobilidade e também a imobilidade do trabalho em certos espaços e momentos históricos. Uma das características desse sistema é a reincidência dos envolvidos, após serem libertos. Se não fosse a liberdade negativa, se houvesse outras alternativas além da precisão, não haveria a peonagem (cf. Moura, 2006).

No que remete à realidade de alguns países latino-ame158 ricanos, veremos que há grandes similitudes em relação ao que se passa no Brasil. A precariedade, vulnerabilidade, mobilidade interna e mesmo internacional - além da peonagem no México (cf. Ortiz, López e Marañon, 2014) - são temas analisados por muitos estudiosos das questões rurais. Enquanto negros e mestiços laboram nos campos brasileiros, nos países vizinhos são os indígenas. Pesquisa recente, com bases em dados quantitativos da FAO (Organização das Nações Unidas para Agricultura e Alimentação) e Cepal (Comissão Econômica para a América Latina), aponta para a permanência do trabalho "indecente" e não o "decente", proposto pela Organização Internacional do Trabalho (OIT) (cf. Dirven, 2015). Ainda que tenha havido aumento da produtividade do trabalho e aumento das exportações das commodities, não ocorreu o mesmo em relação ao salário e as condições de trabalho, segundo Dirven (2015, p. 16).

Nos limites deste artigo, teceremos algumas considerações sobre o México, Argentina, Uruguai, Chile e Equador. 
A migração é um dos pilares básicos da agricultura de exportação do México - principalmente, vegetais e frutas - concentrada no noroeste do país, próxima dos mercados dos Estados Unidos. Dados provenientes da Pesquisa Nacional de Ocupação e Emprego (2010) apontam um total de 2,5 milhões de jornaleiros agrícolas nacionais, sendo $40 \%$ deles indígenas, provenientes do sudeste (Guerrrero, Oaxaca e Chiapas). A mesma pesquisa informa que $90 \%$ não possuem contrato de trabalho e que a maioria migra com todos os membros da família, inclusive crianças. No caso dos ch'oles jovens, provenientes do norte de Chiapas, são recrutados pelos coyotes e muitos deles são levados para os Estados Unidos, fortalecendo as rotas das migrações transnacionais e do trabalho clandestino. Nos campos de hortaliças e de aspargos, a forma de pagamento é por produção (Carrillo, 2014, p. 13).

Outros estudos constataram nessa região - Sinalaoa, Sonora, Baixa Califórnia - que, em razão do processo de reestruturação produtiva necessário para atingir o padrão de qualidade e padronização exigido pelos mercados mexicanos e norte-americanos, houve intensificação do trabalho, sem que isso revertesse em melhorias nas condições laborais. Para tal intento, as empresas implantaram novas formas de gestão, traduzidas em mudanças na divisão sexual, étnica e etária do trabalho. Aos indígenas migrantes, restaram os trabalhos menos qualificados e mal remunerados (cf. Lara e Grammont, 1999). Os autores revelam o eterno nomadismo dos migrantes, a ponto de quase $4 \%$ deles não terem mais residência fixa (cf. Grammont e Flores, 2010, pp. 242-43).

No que tange à produção de flores em Sinalaoa, destinada à exportação para os Estados Unidos, a produção é controlada por empresas japonesas que empregam as mulheres indígenas e migrantes, confirmando a segmentação étnica e sexual. Essas mulheres se destinam às tarefas mais difíceis 
e com salários baixos (cf. Flores, 2012, p. 95-96). Vale ainda mencionar o acordo firmado entre os governos do México e Canadá, pelo qual, há mais de três décadas, trabalhadores e trabalhadoras mexicanos se deslocam temporariamente para o Canadá (Leamington, a capital do tomate) nas plantações de frutas e hortaliças. Trata-se de um mercado de trabalho temporário regulado, tal como no caso dos canaviais brasileiros após o compromisso nacional. A maioria é constituída por mulheres, cujas famílias permanecem nos locais de origem mexicanos. Ainda que seja uma imigração legal, os salários são mais baixos do que os vigentes no Canadá, sem contar que os(as) trabalhadores(as) não gozam dos mesmos direitos vigentes nesse país. $\mathrm{O}$ fato de não falarem inglês é mais um fator que agrava a situação de segregação étnica vivenciada, constituindo-se em uma mão de obra flexível e barata (Quintana, 2004).

No que se refere à Argentina, na região norte da Pata160 gônia, os pesquisadores do GESA (Grupo de Estudios Sociales Agrários) de La Universidade de Comahue desenvolvem várias investigações tendo como universo empírico as plantações de uva, maçã e pera na bacia do rio Negro, para exportação. Os resultados mostram que a maioria dos trabalhadores é constituída pelos tucumanos, provenientes do norte do país. Os homens se destinam às plantações de pera e maçã e a mulheres às da uva. Em menor proporção, há aqueles que provêm de outras regiões do país e também da Bolívia (cf. Bendini e Steimbreger, 2010, pp. 295-96). São destinados, sobretudo, para a colheita e poda. As formas de contratação são por meio de uma cadeia de intermediários - os enganchadores - e por empresas terceirizadas (cf. Bendini, Steimbreger e Trpin, 2013). Nos últimos anos, com o aumento da migração de tucumanos, verificou-se a diminuição da presença dos mapuches, vindos do Chile, que se estabeleceram nas "chacras", situadas nos espaços das plantações. O trabalho envolve todos os membros da família, 
o que permitiu a existência de uma comunidade étnica, "ser chileno”. As mulheres são destinadas aos trabalhos domésticos, ao cultivo de hortas e criação de animais, como porcos, galinhas, coelhos, e à embalagem das frutas, enquanto os homens trabalham na colheita das frutas e também na construção civil nas cidades (cf. Trpin, 2007).

No Uruguai, nas empresas de produção de arándonos (mirtilos) para exportação, predomina o trabalho sazonal, com a participação crescente de mulheres, empregadas na colheita. Critérios sexistas e discriminatórios de naturalização das qualidades femininas, como delicadeza, idoneidade, responsabilidade etc., contribuem para o rebaixamento salarial feminino. Ainda que tenham havido mudanças na legislação, favorecendo os direitos laborais, os trabalhadores recebem salários insuficientes, pagos por produção, são contratados por intermediários (os "contratistas"), que formam redes, definidas por encadeamentos de vários agentes, o que enfraquece seu poder político e social (cf. Riella, Tubio e Lombardo, 2013).

No Chile, observa-se também intensa mobilidade de camponeses indígenas que foram expropriados de suas terras e têm engrossado as rotas para as áreas de fruticultura também para a exportação, como nos demais países analisados. Do mesmo modo, intensificou a participação feminina nessas plantações. Criou-se um verdadeiro corredor migratório de trabalhadores e trabalhadoras temporários da fruta, sobretudo da uva de mesa, cuja fronteira norte se situa no Vale de Copiapó (Atacama) e a fronteira sul em Maule, arregimentados por contratistas. São indígenas mapuches. Ademais, para esse vale, aportam também os indígenas bolivianos e peruanos, homens e mulheres (cf. Valdés, 2015, p. 6).

No Equador, o trabalho nas plantações de flores e brócolis no vale de Cotopaxi é desempenhado, principalmente, por mulheres, descendentes de negros e indígenas. Aí se tem uma das exceções em relação aos casos analisados 
de outros países. A forma de trabalho é permanente e não há intermediários no mercado de trabalho. Isso se deve ao fato de que essa mão de obra é proveniente das unidades camponesas, localizadas no espaço onde as agroindústrias de flores e brócolis se instalaram (cf. Valle, 2015, pp. 7-9). No entanto, Valle observou a intensificação da produtividade pela imposição do trabalho por produção (maior número de "camas de cultivo" e "bonches", pacotes de flores), apesar de menores índices de precarização, que atinge as mulheres e jovens, basicamente. Notou também que o agronegócio de flores e brócolis está promovendo a desestruturação da agricultura camponesa indígena, dado que a força de trabalho aí produzida destina-se cada vez mais às plantações comerciais, indicando estar em meio a um processo de total proletarização (cf. Valle, 2015, p. 14).

$* * *$

As reflexões tecidas no decorrer deste artigo procuraram não apenas retirar a máscara da ideologia sustentadora da produção da agricultura voltada para as commodities e para exportação, trazendo à tona a situação social vivida por homens e mulheres, que se deslocam de uma região a outra e, até mesmo, para outros países, como também apontar a permanência da colonialidade do trabalho, manifesta pelas particularidades históricas de um processo de exploração, onde os marcadores raciais são definidores do valor da força de trabalho de descendentes de indígenas e negros.

O passado histórico das relações escravistas e servis vigentes no Brasil e demais países da América Latina constitui a base para a construção do imaginário social, segundo o qual esses trabalhadores são vistos ainda como "os outros", "inferiores", "incapazes", desvalorizados, sujeitos ao processo civilizatório colonial, que os arranca de suas terras, de seus lugares, forçando-os à mobilidade permanentemente 
temporária, de um canto a outro do continente. Passado que os condena ao processo purgador, usurpador de seus direitos, sentimentos, festas, jeito de falar, cultura e, em alguns casos, de suas vidas.

O objetivo central do texto foi analisar a dimensão racial das relações de trabalho à luz das elaborações sobre raça no imaginário social das diversas realidades tratadas dos países em questão. Em todos eles, a mobilidade espacial (interna e externa) da força de trabalho se constitui no elo que os aglutina. Mobilidade acompanhada de precarização e, em muitos casos, como mostram os estudos citados, vulnerabilidade. Sem registro formal de trabalho, salários baixos, controle exercido pelos "gatos" e "enganchadores", discriminação étnica, contratos temporários de trabalho, insegurança social, além da perda dos referenciais identitários dos lugares de origem, são os resultantes da lógica capitalista no atual momento. Nos casos dos deslocamentos transnacionais (mexicanos para os Estados Unidos e Canadá, por exemplo), ainda há os agravantes linguísticos, que, somados às discriminações étnicas, contribuem ainda mais para o processo de segregação socioespacial de trabalhadores e trabalhadoras.

A mobilidade socioespacial acompanha as necessidades de reprodução dos capitais da chamada agricultura intensiva contemporânea. A realidade brasileira e dos demais países analisados mostra que a flexibilidade do trabalho, que garante os lucros desses empreendimentos, é baseada em critérios étnicos - indígenas, mestiços e negros -, além dos de gênero. As imposições das empresas nacionais e internacionais, ao separarem os membros das famílias dos(as) trabalhadores(as), apropriam-se de suas relações afetivas, gerando uma estrutura de sentimentos caracterizada pela dor e sofrimento moral e emocional.

Contudo, tal como no passado, a resistência contra a violência imposta manifesta-se quer por meio de grandes 
revoltas, quer por recusas individuais. Greves, fugas, reclamações trabalhistas pelos direitos, desistências, lutas por terra e outros recursos naturais, resistências cotidianas, organizações coletivas constituem a imagem conflituosa do campo latino-americano. Assim, termino com a seguinte mensagem a mim enviada no dia 6 de junho de 2015 por Sara Lara Flores:

Te cuento que en México estamos viviendo un momento histórico, pues jornaleros de Baja California (San Quintín) se organizaron e hicieron huelga contra Driscoll y otras empresas freseras, acaban de ganar aumento salarial regulado y dos semanas de "aguinaldo" que es el 13 mes.

\section{Maria Aparecida de Moraes Silva}

164 é livre-docente aposentada da Universidade Estadual Júlio de Mesquita Filho (Unesp), pesquisadora visitante sênior da Capes na pós-graduação em Sociologia da Universidade Federal de São Carlos (UFSCar) e pesquisadora do CNPq.

\section{Bibliografia}

ANTONIL, A. J. 1982 [1711]. Cultura e opulência do Brasil. Belo Horizonte/ São Paulo: Itatiaia/Edusp.

BACCARIN, J. G. et al. 2013. Produção sucroalcooleira no centro sul. Boletim Jaboticabal (SP), n. 41. Disponível em: <BARBOSA, C. M. G. 2010. Avaliação cardiovascular e respiratória de trabalhadores cortadores de cana-de-açúcar no Estado de S. Paulo. Tese de doutorado. São Paulo: Faculdade de Medicina da Universidade de São Paulo.

BARROZO, J. C. 1992. Exploração e escravidão nas agropecuárias da Amazônia mato-grossense. Dissertação de mestrado em Sociologia. Campinas: IFCH, Unicamp.

BENDINI, M.; STEIMBREGER, N. 2010. Trabajadores golondrinas y nuevas áreas frutícolas. In: FLORES, S. M. L. (org.). Migraciones de trabajo y movilidad territorial. México: Conacyt/Miguel Ángel Porrúa. 
BENDINI, M.; STEIMBREGER, N.; TRPIN, V. 2013. Trabajadores estacionales migrantes e intermediación laboral: modalidades tradicionales y novedosas en la fruticultura de Río Negro. In: VII CONGRESO Latinoamericano de Estudios del Trabajo (ALAST), São Paulo, Brasil.

CARRILLO, O. S. 2014. El nuevo mosojäntel ch'ol. Migración y jornaleros indígenas ch'oles en el noroeste de México. In: IX CONGRESO da ALASRU [Asociación Latinoamericana de Sociología Rural], México.

DIMAS, A. 1992. Antonil, a cana e o negro. Revista USP, São Paulo, n. 15, pp. 132-44.

DIRVEN, M. 2015. Transformaciones del trabajo rural en América latina: evolución y precariedades. In: XXXIII CONGRESO da Associação Latino-Americana de Sociologia (LASA), Montreal.

DURKHEIM, E. 1970. La science sociale et l'action. Paris, PUF.

DUSSEL, E. 1993. 1492: o encobrimento do outro. A origem do mito da modernidade. Petrópolis: Vozes.

ESTERCI, N. 1994. Escravos da desigualdade: um estudo sobre o uso repressivo da força de trabalho hoje. Rio de Janeiro: CEDI/Koinonia.

FIGUEIRA, R. R. 1986. A justiça do lobo: posseiros e padres do Araguaia. Petrópolis: Vozes.

FLORES, S. M. L. Los territorios migratorios como espacios de articulación de migraciones nacionales e intrnacionales. Política y Sociedad, v. 49, n. 1, pp. 89-102.

GAUDEMAR, J. P. 1977. Mobilidade do trabalho e acumulação do capital. Lisboa: Estampa.

GOFFMAN, E. 1987. Manicômios, prisões e conventos. 2. ed. São Paulo: Perspectiva.

GRAMMONT, H. C.; FLORES, S. M. L. 2010. Productive restructuring and "standardization" in Mexican horticulture: consequences for labour. Journal of Agrarian Change, v. 10, n. 2, pp. 228-50.

GUIMARÃES, A. S. 2003. Como trabalhar com "raça" em sociologia. Educação e Pesquisa, São Paulo, v. 29, n. 1, pp. 93-107.

HEGEL, G. W. F. 1946. Lecciones sobre la filosofía de la historia universal. Buenos Aires: Revista de Ocidente Argentina. Tomo I.

LAAT, E. F. 2010. Trabalho e risco do corte manual da cana-de-açúcar. Tese de doutorado em Engenharia de Produção. São Paulo: Universidade Metodista de Piracicaba.

LARA, S. M.; GRAMMONT, H. C. 1999. Reestructuración productiva y mercado de trabajo rural en las empresas hortícolas de Sinaloa. In: GRAMMONT, H. C. (org.). Empresas, reestructuración productiva y empleo en la agricultura. México: IIS-UNAM/Plaza y Valdés. 
MARTINS, J. S. 1979. O cativeiro da terra. São Paulo: Livraria Editora Ciências Humanas.

1995. A reprodução do capital na frente pioneira e o renascimento da escravidão no Brasil. Tempo Social, São Paulo, v. 6, n. 1-2, pp. 1-26.

MARX, K. 1978. Le capital. Livre Premier, Tome I. Paris: Éditions Sociales. MEILLASSOUX, C. 1976. Mulheres, celeiros e capitais. Porto: Afrontamento.

MOURA, F. A. 2006. Escravos da precisão. Economia familiar e estratégias de sobrevivência de trabalhadores rurais em Codó. Dissertação de mestrado em Ciências Sociais. São Luís: Universidade Federal do Maranhão.

ORTÍZ, J.; LÓPEZ, D.; MARAÑON, B. 2014. Trabajo forzoso en México. La experiencia del peonage en Chiapas durante los siglos XIX y XX. In: IX CONGRESO de ALASRU [Asociación Latinoamericana de Sociología Rural], México.

PERO Vaz de Caminha. Edição de base: Carta a El Rei d. Manuel. Dominus: São Paulo, 1963. Disponível em: <http:/ /www.biblio. com.br/defaultz.asp?link=http:/ / www.biblio.com.br/conteudo/ perovazcaminha/carta.htm>. Acesso em: 20 mar. 2015.

QUIJANO, A. 2005. Colonialidade do poder, eurocentrismo e América Latina. In: LANDER, E. (org.). A colonialidade do saber: eurocentrismo e ciências sociais. Perspectivas latino-americanas. Buenos Aires: Clacso.

QUINTANA, O. B. 2004. Políticas laborales de género, trabajo transnacional y experiencias vividas: trabajadores y trabajadoras agrícolas migrantes en Canadá. Boletín Oficial del Instituto Nacional de Antropología e Historia, n. 74, Nueva Época, pp. 96-111. [Trabajadores agrícolas temporales mexicanos en Canadá, 1974-2004].

RIELLA, A.; TUBÍO, M.; LOMBARDO, R. 2013. Cadenas globales y trabajo rural: la producción de arándonos en Uruguay. Revista de Ciencias Sociales, DS-FCS, v. 26, n. 32, pp.113-32.

SILVA, M. A. M. 1990. Como "expulsar o camponês do proletário".

Travessias, São Paulo, Edunesp, v. 8, n. III, pp. 5-12. 1992. As andorinhas. Nem lá, nem cá. Vídeo. Araraquara: Unesp. 1999. Errantes do fim do século. São Paulo: Edunesp. 2013. "Sabe o que é ficar borrado no meio da cana?". Estudos Sociedade e Agricultura, Rio de Janeiro, UFRRJ, ano 21, n. 2. pp. 359-91. http://r1.ufrrj.br/esa/V2/ojs/index.php/esa/article/view/373/368. 2014. A nova morfologia do trabalho nos canaviais paulistas.

In: ANTUNES, R. (org.). Riqueza e miséria do trabalho no Brasil III. São Paulo: Boitempo. 
2015. Melancolia e trabalho. In: NOGUEIRA, M. D. P. (org.). Vale do Jequitinhonha: gênero e migração. Belo Horizonte: Ed. UFMG.

SILVA, M. A. M. et al. 2011. Os (não direitos) dos trabalhadores rurais: "a permanência do intolerável”. In: CANUTO, A. et al. (orgs.). Conflitos no campo. Brasil 2011. Goiânia: CPT.

2014. Quando a máquina "desfila", os corpos silenciam: tecnologia e degradação do trabalho nos canaviais paulistas. Contemporânea, PPG/ Sociologia, UFSCar, n. 4, pp. 85-116. Disponível em: <http://www. contemporanea.ufscar.br/index.php/contemporanea>. Acesso em: 1 out. 2014.

TODOROV, T. 1999. A conquista da América: a questão do outro. São Paulo: Martins Fontes.

TRPIN, V. 2007. Identidades en movimiento. Famílias chilenas en la fruticultura del Valle de Rio Negro, Argentina. Cadernos Pagu, n. 29, pp. 227-55.

VALDÉS, X. 2015. Trabajo temporal y emancipación precaria. In: XXXIV CONGRESSO da Associação Latino-Americana de Sociologia (LASA), Porto Rico.

VALLE, L. M. 2015. Assalariados rurales em territórios em predomínio del agro negocio: el caso Cotapaxi-Ecuador. In: XXXIV CONGRESSO da Associação Latino-Americana de Sociologia (LASA), Porto Rico.

VERÇOZA, L. V. 2016. Os saltos do "canguru” nos canaviais alagoanos. Um estudo sobre trabalho e saúde. Tese de doutorado em Sociologia. São Carlos (SP): UFSCar.

WALLERSTEIN, I. 1989. The modern word-system. New York: Academic Press.

2006. Impensar a ciência social. Os limites dos paradigmas do século XIX. Aparecida, SP: Ideias e Letras. 


\section{TRABALHO RURAL: AS MARCAS DA RAÇA}

\section{MARIA APARECIDA DE MORAES SILVA}

Resumo: Atualmente, em grande parte dos estudos rurais brasileiros, o trabalho assalariado não faz parte dos temas investigados. Por outro lado, nos estudos referentes à produção das commodities, por meio de máquinas com tecnologias avançadas, o trabalho é ocultado e, até mesmo, negado. Diante dessas ausências, proponho uma reflexão capaz de trazer à cena os(as) trabalhadores(as) rurais e desvendar os marcadores étnico-raciais que os(as) remetem aos porões da escala social. Baseando-se na metodologia da história oral de minhas pesquisas e na análise comparativa de vários estudos latino-americanos, busco a compreensão da permanente situação de degradação do trabalho rural no capitalismo contemporâneo, no contexto das marcas históricas da colonialidade.

Palavras-chave: Trabalho Rural; Raça; Colonialidade.

\section{RURAL WORK: THE MARKS OF RACE}

Abstract: Currently, in most Brazilian rural studies, wage labor is not part of the research topics. Moreover, in studies regarding the production of commodities by means of machines with advanced technologies, the work is hidden or even denied. Given this situation, I propose a reflection that may bring to the scene the rural workers (man and women) and uncover the racial markers that refer to the basements of the social ladder. Based on the oral history methodology of my research and on the comparative analysis of various Latin American studies, I seek to understand the permanent degradation of the rural labor situation in contemporary capitalism in the context of historical marks of coloniality.

Keywords: Rural Work; Race; Coloniality.

Recebido: 20/01/2016 Aprovado: 07/05/2016 